\title{
Philosophy Thoughts Affect Costume
}

\author{
Weiwei Liu \\ College of Art and Appareluages, Tianjin Polytechnic University, Tianjin 300160, China \\ E-mail:1weei@126.com
}

\begin{abstract}
Apart from beautifying and protecting human body, costume itself is a symbol of culture and an image of some thoughts. Furthermore, different origins of Western and Eastern civilizations and various cultures for thousands of years have created distinctive varieties in costume. In Chinese history of apparel, whether the two forms of yi and shang (upper garment and the lower garment), i.e. skirts, or shenyi, i.e. qunju usually worn by women, and the later changes in color or in structure or in details, costume has been deeply affected by Confucianism, Taoism and Buddhism and other traditional Chinese thoughts. Among them, Confucianism has given the greatest. The Western costume is completely different from that of China. Westerners have paid more attention to the pursuit of their own natural beauty, the rational exploration and the worship of religion and theology.
\end{abstract}

Keywords: Philosophy thoughts, Costume, Arts

Guo Moruo once said that costume is the symbol of culture and the image of thought. The costume history of the East and the West for thousands of years has witnessed a colorful and changeable picture. From the evolution of clothing, we can see the changes of history, development of economy and cultural aesthetic evolution.

\section{Most scholars believe that the oriental philosophy originates from the Yijing, or can be traced back to the earlier concepts of Yin and Yang.}

The later Eastern philosophy, the development of science and theoretical grounds are all from these traditional concepts.

\subsection{The Confucian thought in the Spring and Autumn Period has produced profound influence on ancient China and the} whole Chinese wedding dress.

Zhouyi is read that, emperor Huangdi, emperor Yao, and emperor Shun worn nutant clothes to rule the country, which probably adopts the meaning of Qian and Kun (heaven and earth). Confucianism believes that the structure of $y i$ and Shang(upper and lower garment) is from the symbol of heaven and earth, nobleness and humbleness, male and female, yin and yang. $Y i$ is from Qian, symbolizing heaven, nobleness and male. Shang is from Kun with the meaning of earth, humbleness and female. Clothing does not only exist in the appearance of a person, but in the material world and in spiritual world linking with the thoughts and behavior of people. Thus the notion of "the unity of clothing and people" is produced and melted into every aspect of clothing design.

China is known as a country of amenity and a kingdom of clothing, which is inseparable to the Confucian thought. Among numerous Confucian figures, Confucius is the most representative. He says in a book, Dadaili, "if you meet others, you must wear decent and tidy clothes. No primping is impolite. Impoliteness means no respect. No respect means no amenity. No amenity signifies less achievement." What kind of clothes and ornaments a man of honor should wear is strictly prescribed. Confucius in another book, Lunyu, said that "men of honor wear righteous clothes". Precisely for this reason, costumes in early Chinese community are solemn. The whole body is wrapped up against bare skin.

As for taste of colors, Confucius tends to emphasize the psychology, social background and social position of the wearers. He prefers bright and pure colors. Of ancient Chinese wedding clothes, Zhou dynasty prefers black and red, Tang dynasty blue and green, Ming dynasty green and red, which are all subject to the deeply influence given by Confucius and Confucianism.

In the previous dynasties of history, kings and subjects, nobles and civilians wear distinct clothes. This phenomenon is also closely related to the Confucian thought. Confucian thought is strict and full of hierarchical ideas. Different identities should wear corresponding clothes on different occasions. Chinese costume, on the one hand, stresses the proper use of clothes. On the other hand it stresses the harmony of ethics and the laws of nature. "Every feudal court in history has its own prescriptions to safeguard the authority of its rulers. But the changes of clothing styles are limited in size, color or ornaments. As far as aesthetics is concerned, it still does not exceed the Confucian thought of the dressing amenity. 
1.2 The medieval ages saw the development of classical aesthetics in China. Chinese indigenous Taoism, and foreign Buddhism and other religions have produced a positive impact on China's clothing to some extent.

Each dynasty gives a critical requirement for the colors of the clothes. Different color has different meaning. Xia dynasty favors black, Yin dynasty white, Zhou dynasty red, Qin dynasty black, Han dynasty red, Tang dynasty yellow, and Ming dynasty red, which all have close relationship with the Taoist culture. It is said that blue, red, yellow, white and black are orthochromatic. And the others are secondary colors. There are wood (is equivalent to blue), fire (red), earth (yellow), gold (white) and water (black) in "five Xing" and the four directions of east (blue), west (white), south (red), and north (black). Earth, gold, water, wood and fire give birth to each other, which also means their controls of one another. Shang dynasty favors white but white is west gold. Gold controller is fire and fire is red in five Xing. Zhou dynasty takes place of Shang dynasty, so Zhou dynasty chooses red to signify that fire conquers gold.

On the other side, China emphasizes dressing amenity and harmony of people and clothes. People want to show their appearance and self-restraint, so they stress grace and decency. For example, the wedding clothes are grand, formal, stringent and generous and totally cover the bodies of wearers. Folk costumes also follow the aesthetics of "harmonious coexistence". Chapeaus of Ming Dynasty symbolize the unity of the country, the universal prosperity, and the harmony of man and nature. The standardization and golden mean of costume fully embodies the Taoist aesthetics in Chinese Costume.

\subsection{The religion of Buddhism, just like Taoist thought, also produces an indelible impact on ancient Chinese costume.}

The period of Wei, Jin, South and North Dynasties saw the prevalence of getting dizzy with success, transcending the exterior social regulations and achieving natural morality of inner world. The wedding apparel is also not stick to one pattern. It is not affected or pretending. On the contrary it is very natural in detail. Loose robe and big sleeves became the main feature of the then clothing.

Costume entered a period of unprecedented prosperity in Tang Dynasty. Its aesthetic culture is basically from the extension of Confucianism and Taoism thoughts in Wei dynasty and Jin dynasty, with free, open and dynamic characteristics. Suit-dress is loose with big and big sleeves, décolleté and off-shoulder neckline. Ever since Buddhism came to China, its patterns have been used widely for the clothing by now. For example, the Eight Cimelias in Buddhism mean the Eight Lucks. The Wheel symbolizes the magical power, which can be inherited for ages. Gyration signifies the sound of Buddhism, which can be heard all over the world. The Umbrella symbolizes the free spread of Buddhism. The flower is Lotus, symbolizing that Buddhism is pure and it can help all flesh to get rid of dirt and filth. The Can is originally the Precious Bottle, which signifies the profound, powerful and far-reaching Buddhism and the sufficient felicities and witnesses. Fish symbolizes the unlimited vitality and freedom of Buddhism. The long Plate, also named Luck Knot, is used to refer to the powerful force of Buddhism.

Throughout the entire Eastern philosophy, different theory appears one after another. The issues discussed by different schools mainly focus on the political ethics, that is, norms and the concern for people. The Eastern costume culture represented by China has been deeply affected by the traditional oriental culture. It stresses the abstract implications of the linear shapes and heraldry.

\section{The oriental philosophy, unlike the Western one, has not a distinct starting point.}

It is not similar to early ancient Greek philosophers who tried to separate from the tradition and create a new one. In studying the Western philosophy, Greek philosophy is an integrant link that can not be avoided. The ancient Greek philosophy is the source of Western Philosophy. Thought there appeared different philosophy branches after ancient Greek philosophy, what they inherited is still the philosophical spirit of ancient Greece and displays the concern for various causes of a phenomenon and the pursuits for certainty.

The traditional practice of the Western philosophy of maintaining the tradition of "ratiocination" and "truth-seeking" makes them accustomed to discussing rules or laws by reasoning. In costume, they show a natural pursuit of the beauty of body or objects. Ancient Greek city-states of slavery had the pursuit for beauty of the human nude. They even took healthy and beautiful human body as an example to praise as a hero on the earth and as God in heaven, which is influenced by their philosophy of favoring human body or objects of aesthetics.

2.1 In the early clothing design, people are the principal part while clothes are only accessory and faithfully subordinated to the body and the physical activities.

Clothes are wrapped around the body without being cut or sewn. They are invisible. The ancient Egyptian drapery is a good example in case. Without human body, it is just a piece of cloth.

Apparel aims at showing the beauty of human bodies and self-expression. To tog is to show off the beauty of selfhood and display individuality. So clothes are just attachments to a human body. A man can exaggerate his broad and majestic physical figure by the stuffs of clothes. A woman can give prominence to her second female feature by wearing a tight bra and a pannier.

The Westerners attach great importance to the rational and scientific things. We can discover those beautiful and reasonable shapes from numerous foreign clothes and paintings and buildings. Perhaps it is the viewpoint of paying 
more attention to geometric shape that results in the unexpected situation of ignoring color function.

\subsection{European religion and theology have given a great influence on costume.}

The religions of ancient Rome and ancient Egypt provided the gods in Pantheon and the images of goddesses. Each god represents one aspect of life. Meanwhile, every aspect of life has infiltrated into wedding ceremony to give symbolic significance to wedding clothes and their components. A bride wears a tunic robe with a Hercules knot and a hair style of the kitchen God. Wearing wig in terms of the ancient Egyptians is of far-reaching significance. It is good-looking and it bears a religious and social meaning.

In ancient Greece, over-makeup was refused and reproached at that time. Influenced by Greek goddess Aphrodite and Pandora and Spartan Lee Cougar, Greek women pursued the notion of "nature is beauty". And the notion almost influenced all countries in ancient times. They had a winding, unfettered character in wedding clothes with no custom of corset.

In the Middle Ages, Christianity had absolute ruling status. And the various parts of the social life revolved around religion. "The combination of Christianity and secular rights makes clothing the most powerful tool with which they maintain their religious rights and secular rule. Religious thought is the durance of human nature and controls people's minds, which makes clothing break away from the close integration of the human body." Christian aesthetic perspective is simple but mysterious. It believes that "it is God that is something beautiful. So what belongs to the beautiful type are from God." It considers that flesh and blood is the source of evil. "Women are the evil serpents on the way of thorns. They are created by devils. So the creation by devils must be occluded". So clothing as a tool to cover up the sins should be very simple and conservative. Christian abstinence is transferred and reflected on clothing. "People restrain and control themselves in order to show their passions for Christianity. The clothes they wear are plain, loose but close, and cover a body almost airproof." Strongly advocating abstinence and repressing human nature has given birth to a desire and impulse that people dress up in the name of the glory of God. Thus Gothic clothing appears in the exaggerated panache. "The pointed shoes and pointed hat chimed with the church steeple have formed the aesthetic philosophy in a religious environment."

However, Westerners advocating natural beauty of the human body have never been interrupted. It has become the traditional aesthetics of Westerners that comes down in one continuous line. From the costume of noble women in ancient palaces to the recent and modern high fashionable dress, all emphasize expressing the beauty of human body. The means adopted are shaping the body inside and exposing skin outside. Thus it can be seen that it is ancient Greek philosophy that causes the Western costume in constant pursuit of objective forms and the beauty of human body.

In short, ideological and cultural differences between the East and West in clothing can be explored in the following aspects. First, in the east, a human being and his clothes are interdependent. Clothing reflects the mental outlook of the wearer. The harmony of heaven and human beings can be used to denote the perfect realm of wearer and his clothes. While in the West, clothes are only appendant. People pay more attention to the natural beauty. Secondly, oriental clothes in shaping are mainly planar. Whether yi or shang or shenyi loose robe with long and big sleeves or narrow sleeves have resulted from the infiltration of Chinese traditional thoughts. On the other hand, it is the results demanded by a long-term agricultural society of China. The West enters the industrial society early and the clothing modeling is also changed rationally to be three-dimensional. While it specifically highlights the natural beauty of human beings, more functions and rationality have been increased. Thirdly, Oriental clothing has more colors. Whether yi or shang or shenyi, although there is some changes in size, their overall shape has been little changed. But the colors of the clothes are totally different from generation to generation. However, clothes in the West have more changes in shape than in color.

In the colorful Eastern and Western clothing history in the constant movement, we can clearly see that apparel has been influenced by aesthetic consciousness of different times. The earliest function of clothing is to cover human body. With the passage of time and the evolution of history, clothing has been in the course of integration and accumulation. It has developed the useful and discarded the useless, and gradually improved the degrees of civilization. By now it has become the symbol of personality. Clothing is always reflecting something of the history to which it relies on with its material and spiritual unique. Clothing can not develop beyond its social foundation. It is ancient Greek Christianity and Eastern Confucian philosophy that have given great influences on costume.

\section{References}

Liyan, Zhou. Dongsheng Chen \& Xiaojuan,Wei. (2003).Comparison of Chinese and Western Costume Culture. Journal of Zhejiang Textile and Fashion College. (9).

Na, Tang. Yan Xiu, Wang \& Guixia,Yu. (2001).Verifying the different reasons of Western clothing styles. Journal of Tianjin Institute of Science and Engineering Institute. (17).

Robert lamping-fai. (1986). Local Tradition Chinese Wedding. Hong Kong: Hong Kong Museum of History. (5).

Ye Sun. (2000). Apparel and Religious Culture. Journal of Textile Engineering Institute. (5). 